\title{
A Model of Learner Development Activity Arrangement according to Buddhadhamma for Students in Schools under the Secondary Educational Service Area Office
}

\author{
Phra Watchara Devasirinago ${ }^{1}$, Boonchert Chamnisart ${ }^{2}$, Rawing Ruangsanka ${ }^{3}$, Lampong Klomkul ${ }^{4}$ \\ 1,2,3,4 Faculty of Education, Mahachulalongkornrajavidyalaya University \\ ${ }^{1}$ watchara_2536@ hotmail.com, ${ }^{2}$ boonchurd@hotmail.com, ${ }^{3}$ billionwings@ hotmail.com, ${ }^{4}$ research.mcu@gmail.com
}

\begin{abstract}
The purposes of this research were 1) to study the condition of learner development activity arrangement for students in schools under the secondary educational service area office, 2) to develop a model of learner development activity arrangement according to the Buddhist principles for students, and 3) to propose a developed model. Mixed methods research was used for research design. Data were collected by using documentary study, in-depth interview with ten school administrators and focus group discussion with nine experts. The research instruments used in this study were questionnaires, interview form and issue for focus group discussion. The samples of quantitative study were 388 administrators and teachers under the office of the secondary educational service area selected by the multistage sampling. Quantitative data analysis was to validate the structural equation model with the empirical data whereas qualitative data was analyzed by content analysis and analytic induction. Result indicated that 1) the overall problems to organize the learner development activities were (1) learner development activities, (2) assessment of learner development activities, and (3) the prototype model of learner development activity arrangement according to the new normal, respectively. 2) A developed model consisted of four components which were (1) the learner development activities, (2) Selftraining with Tri-sikkha (The Threefold Training), (3) the prototype of learner development activity arrangement according to the new normal, and (4) the assessment of the learner development activity. 3) The developed model was fit with the empirical data based on the statistical values, chi-square $=73.13, \mathrm{df}=55, \mathrm{p}=.052, \mathrm{RMSEA}=.029$. From the casual relationship model, it was consistent with the actual situation of learner development activity rearrangement according to the Buddhist principles for students will result to a happy coexistence that was necessary to have the components of training content according to the threefold training principles consisted of practicing oneself. It was used as an important part in determining the scope of the learning content or content in designing the learning process for students to practice through practical activities that links to the learner development activity.
\end{abstract}

Keywords

Model of Learner Development, Activity Arrangement, Buddhadhamma

Article Received: 10 August 2020, Revised: 25 October 2020, Accepted: 18 November 2020

\section{Introduction}

At present, Thai society has changed over time. Which is the age of information with innovation and technology Modern science that emphasizes the quality of human beings in society. In terms of material and values, this change causes many problems in life, such as health problems, economic problems. Unemployment problem Problems building the family status of the family cannot be complete. Problem of inequality and the degradation of the moral, ethical, and cultural issues mentioned above is a problem that results in psychological problems and affect further social problems which will find that people in the nation are facing now because of the psychological development that was not developed in time material prosperity and values from this change. Therefore, leading to more serious problems, most worrisome is the psychological problem is a fundamental problem of many other problems because the mind is the most important component that makes people perform various deeds, both good and bad karma Buddhist principles gave thought and reminders about life problems that is because of his own karma or his actions.

Developing people to have potential and quality plus the need to have morality and ethics that exploit knowledge in order to be developed for the better must give him the role of education in society let him show his full potential and give him the opportunity to be assertive, be yourself, respect the decision, listen to comments and suggestions to develop for further development. It also gave him the opportunity to perform on stage to the fullest in education. Because everyone can perform on stage to their full potential and quality, it is imperative that quality education be undertaken in order to maximize the potential of that person's potential and develop. It makes people know, think, analyze, synthesize and dare to face the problems that lie ahead, creativity, learn to learn by yourself and from those around you, able to adapt to changes that occur rapidly, having principles, knowing self-reliance and able to live in a happy society[1]. Current situation point out concerns of imbalanced development aimed at creating rapid economic prosperity make individuals and society including structures and administrative mechanisms and management that cannot be adapted in time. There is an imbalance between physical development and mental development causing stress, anxiety, and failing to adjust. There is an imbalance between physical development and mental development causing many problems especially to children and youth in school age such as mental health problems causing stress, anxiety, and failing to adjust lack of self-worth, more suicide problem of sexual harassment, various forms of violence or abuse, drug problems, failure to achieve academic and professional success. In particular, the form of educational activities for students' development which is an important foundation for the development of the future youth of the 
nation. The foundation of national development must begin with the development of the quality of the people in Thailand.

Learners development activities aimed at students to develop themselves according to their potential. All-round development for a complete human being, physically, intellectually, emotionally and socially to have the ability and foster a person with virtue, ethics, discipline, and take responsibility cultivate the values and subconsciousness of social contribution able to handle themselves and accept open-minded thinking positively in living happily with others. There are 3 types of student development activities: guidance activities, student activities and activities for society and the public benefit. Learner development activities are structured activities with a variety of formats to achieve a defined objective. It enables teachers and research authors to organize a variety of activities [2].

From the current condition found organizing student development activities in educational institutions, most of the activity teachers lack knowledge and understanding in organizing activities and skills in organizing activities which results in students not meeting the interests or needs of learners. It also instills desirable qualities in students according to their intended objectives. Therefore, the researcher is interested in creating a model for student development activities according to the Buddhist principles for that student. It must be full and full of physical and mental, social, emotional and intellectual potential in today's society. It is important to apply the Buddhist principles of Buddhism to be applied in the formulation of learner development activities because in today's society. There are many problems how much depends on the process of applying the principles of Buddhism to solve problems in that organization. Whether it is the Dittatha Thammikattha, the 4 main benefits, and the threefold to present and develop a format for organizing activities by applying Buddhist principles and integrating them in solving problems and improving the quality of life of the learners and leading to the ultimate goal of organizing learner development activities, which is a form of activity development for students. It is a perfect human being, good, intelligent, capable, happy and indispensable, and must have virtue. It is an ethical approach to model makers to further develop student activities in the 21 st century [3].

\section{Research Objectives}

The purposes of this research were 1) to study the condition of learner development activity arrangement for students in schools under the secondary educational service area office, 2) to develop a model of learner development activity arrangement according to the Buddhist principles for students, and 3) to propose a developed model of learner development activity arrangement according to the Buddhist principles for students.

\section{Research Method}

Mixed methods research was used for research design. Data were collected by using documentary study, in-depth interview with ten school administrators and focus group discussion with nine experts. The research instruments used in this study were questionnaires, interview form and issue for focus group discussion. The samples of quantitative study were 388 administrators and teachers under the office of the secondary educational service area selected by the multistage sampling. Quantitative data analysis was to validate the structural equation model with the empirical data whereas qualitative data was analyzed by content analysis and analytic induction.

Step 1 Study the condition of organizing student development activities for students under the Office of the Secondary Educational Service Area, there are 3 steps: 1) study from documents, study conditions from documents related to the format, meaning, types, guidelines for organizing learner development activities, concept of learning activities, Buddhist Dhamma Trisikha 3, and study the information of the school. Source: from books, textbooks, articles, related research, website. Results: The state of student development activities for students. 2) Study from distribution of questionnaires about the condition of student development activities for students under the Office of the Secondary Educational Service Area. The sample consisted of 400 teachers. Data analysis: percentage, frequency, mean. 3) Study of the interview about the conditions of student development activities for students under the Office of the Secondary Educational Service Area from experts of 5 people using Snow Ball technique and select a specific set criteria for selection.

Step 2: Develop a model for organizing activities for learners according to Buddhist principles for students under the Office of the Secondary Educational Service Area, there are 3 steps as follows: 1) Drafting a model for student development activities based on Buddhist principles for students under the Office of the Secondary Educational Service Area, 2) Develop a model for organizing activities for learners according to Buddhist principles for students under the Office of the Secondary Educational Service Area by discussion group of resources: experts / academics / school administrators by selecting a specific type of 10 people. 3) Examine the pattern of student development activities according to Buddhist principles for students under the Office of the Secondary Educational Service Area by distributing questionnaires, data source: a sample group of 388 teachers randomly sampled.

Step 3 presents the form of organizing activities for learners according to Buddhist principles for students under the Office of the Secondary Educational Service Area by revising, revising and presenting as follows: Revise, improve, and present the form of student development activities according to Buddhist principles for students. Under the Office of the Secondary Educational Service Area, Tool: Study Document Outcome: a causal relationship model, management of Buddhist learner development activities for students under the Office of the Secondary Educational Service Area with empirical data.

\section{Research Findings}

1) Opinions about the condition of organizing student development activities for students under the Office of the Secondary Educational Service Area. The results of the research found that the problem of learner development activities for students under the Office of the Secondary 
Educational Service Area. Overall, it was at the high level with the mean (4.18) and when considered individually in the teacher side with the highest average in the high level, in descending order, the student development activities (4.19), the assessment, Organized learner development activities (4.17) and the areas with the lowest average at the high level were the prototype of the student development activities according to the new path (4.17).

Table 1 Shows the results of the analysis of mean values. and standard deviation comments on the condition of organizing student development activities for students Under the Office of the Secondary Educational Service Area

\begin{tabular}{l|l|l|l|c}
\hline \multicolumn{2}{c|}{$\begin{array}{c}\text { Components of organizing } \\
\text { activities for learner } \\
\text { development }\end{array}$} & \multicolumn{3}{|c}{ State of Problem } \\
\cline { 3 - 5 } & $\overline{\mathbf{X}}$ & S.D. & $\begin{array}{c}\text { Interpret } \\
\text { results }\end{array}$ \\
\hline 1 & $\begin{array}{l}\text { Learners Development } \\
\text { Activities }\end{array}$ & 4.19 & 0.04 & High \\
2 & $\begin{array}{l}\text { Model of student } \\
\text { development activities } \\
\text { Assessment of student } \\
\text { development activities }\end{array}$ & 4.17 & 0.02 & High \\
\hline \multicolumn{2}{l|l}{ Total } & 4.18 & 0.01 & High \\
\hline \hline
\end{tabular}

The results of basic statistical analysis of the variables used in the model. There are 14 indicators used to measure 4 latent variables: 1) Learner Development Activity (STACT), 2) Assessment of Learner Development Activity (ASSESS), 3) Trisikha Practice (TRISIK), 4) Model. The aim of the new learner development activities (NORMA) (HAPLIVE) was to study the distribution and distribution characteristics of each observable variable. The statistics used were mean, standard deviation (SD), minimum score (Min), maximum score (Max), dispersion coefficient (CV), skewness (Sk), and Kurtosis $(\mathrm{Ku})$ results were analyzed, each of the variables were as follows.

When considering organizing learner development activities (STACT), it was found that overall, learner development activities Was at a high level (Mean= 4.19), which when considered on each side found that Guidance activities (Mean=4.23) followed by social and public interest activities (Mean=4.20) and student activities (Mean=4.14), respectively. When considering the distribution coefficient (CV) of the variables, it was found that the variables were distributed no different very common. The value was between $4.14-23 \%$. When considering the skewness (Sk) of the variable, it was found that all the variables were distributed in a left skewed manner. (Negative skewness value) indicates that the data of every variable is higher than the mean. When looking at the kurtosis $(\mathrm{Ku})$, it was found that all the variables had a higher than normal distribution curve. (value greater than 0 ) indicates that all variables have little distribution of information.

When considering the components of the assessment of student development activities (ASSESS), it was found that, overall, the fundamentals of reflection were at a high level $(\mathrm{Mean}=4.17)$. The recommendations were the highest average (Mean=4.17), followed by the criteria of judging (Mean=4.17), the assessment guidelines (Mean=4.15) and the corrective measures for students who did not meet the criteria (Mean=4.14), respectively. Considering the distribution coefficient (CV) of the variables, it was found that the variables did not differ greatly. The value was between $4.14 \%-4.18 \%$. When considering the skewness (Sk) of the variable, it was found that all the variables were distributed in a left skewed manner (Negative skewness value) indicates that the data of every variable is higher than the mean. When looking at the kurtosis $(\mathrm{Ku})$, it was found that all the variables had a higher than normal distribution curve (value greater than 0 ) indicates that all variables have little distribution of information.

When considering the training according to the Trisikha principle (TRISIK), it was found that the overall training according to the Trisikha principle was at a high level (Mean=4.13). In terms of mental training for concentration, the highest average (Mean=4.14) followed by rational thinking (Mean=4.13) and practice according to the precepts (Mean=4.12), respectively. The variables were found to have a very different distribution. The value was between $4.12 \%-4.14 \%$. When considering the skewness (Sk) of the variable, it was found that all the variables were distributed in a left skewed manner. (Negative skewness value) indicates that the data of every variable is higher than the mean. When looking at the kurtosis $(\mathrm{Ku})$, it was found that all the variables had a higher than normal distribution curve. (value greater than 0 ) indicates that all variables have little distribution of information.

When considering the model of activities for learner development along the new path (NORMA), it was found that the overall level was at a high level (Mean= 4.16). There was the highest average (Mean $=4.18)$, followed by training in providing services that benefit oneself and the public (Mean=4.18), cultivating a consciousness for social benefit (Mean= 4.17) and promoting the knowledge group. Learned all 8 groups $($ Mean=4.12), respectively. When considering the distribution coefficient (CV) of the variables, it was found that the variables did not differ greatly. The value was between $4.12 \%-4.18 \%$ When considering the skewness ( $\mathrm{Sk}$ ) of the variable, it was found that all the variables were distributed in a left skewed manner (Negative skewness value) indicates that the data of every variable is higher than the mean. When looking at the kurtosis $(\mathrm{Ku})$, it was found that all the variables had a higher than normal distribution curve. (value greater than 0) indicates that all variables have little distribution of information.

The results of the analysis of consistency with empirical data of the model, model of student development activities based on Buddhist principles for students Under the Office of the Secondary Educational Service Area. 
Table 1 Results of the analysis of consistency with empirical data of the model (in Thai)

\begin{tabular}{|c|c|c|c|c|c|c|}
\hline \multirow{2}{*}{$\begin{array}{l}\text { ตัวแปรผล } \\
\text { ตัวแปรเหตุ }\end{array}$} & \multicolumn{3}{|c|}{ TRISIK } & \multicolumn{3}{|c|}{ NORMAL } \\
\hline & TE & IE & DE & TE & IE & $\mathrm{DE}$ \\
\hline \multirow[b]{2}{*}{ STACT } & $.68^{* *}$ & - & $.69 * *$ & $.4 q^{* *}$ & $32^{* * *}$ & $12^{* *}$ \\
\hline & (.09) & & $(0.09)$ & $(.07)$ & (.07) & $(.08)$ \\
\hline ASSESS & $\begin{array}{l}26^{* *} \\
(099)\end{array}$ & - & $.26 *$ & $\begin{array}{l}.56^{* * *} \\
(07)\end{array}$ & $\begin{array}{l}-12^{* *} \\
(04)\end{array}$ & $.43^{* *}$ \\
\hline \multirow[b]{2}{*}{ TRISIK } & (1) & & & $.46^{* *}$ & & $.46^{-* *}$ \\
\hline & & & & $(.07)$ & & $(.07)$ \\
\hline \multicolumn{4}{|c|}{ ไค-สแควร์ $=73.13 \mathrm{df}=55 \mathrm{p}=.052$} & $\mathrm{I}=97, \mathrm{AGFI}$ & $.95 \mathrm{RMR}=.0$ & 11 \\
\hline ตัวแปร & STACT1 & STACT2 & STACT3 & ASSESS1 & ASSESS2 & ASSESS3 \\
\hline ความเที่ยง & 695 & .759 & .873 & .785 & .770 & .779 \\
\hline ตัวแปร & ASSESS4 & TRISIK1 & TRISIK2 & TRISIK3 & NORMAL1 & NORMAL2 \\
\hline ความเที่ยง & .780 & .870 & .842 & .773 & .774 & .802 \\
\hline ตัวแปร & NORMAL 3 & NORMAL 4 & & & & \\
\hline ความเที่ยง & .812 & 861 & & & & \\
\hline \multicolumn{2}{|c|}{ สมการโครงสร้างตัวแปร } & TRISIK & NORMAL & & & \\
\hline \multicolumn{2}{|l|}{ R SQUARE } & .845 & .954 & & & \\
\hline \multicolumn{7}{|c|}{ เมทริกซ์สหสัมพันธ์ระหว่างตัวแปรแฝง } \\
\hline \multirow{2}{*}{$\begin{array}{l}\text { ตัวแประผง } \\
\text { TRISIK }\end{array}$} & \multicolumn{2}{|c|}{ TRISIK } & NORMAL & STACT & ASSESS & \\
\hline & \multicolumn{2}{|c|}{1.000} & & & & \\
\hline NORMAL & \multicolumn{2}{|c|}{.952} & 1.000 & & & \\
\hline STACT & \multicolumn{2}{|c|}{.912} & .933 & 1.000 & & \\
\hline ASSESS & \multicolumn{2}{|c|}{.868} & .945 & .894 & 1.00 & \\
\hline
\end{tabular}

In the data analysis of this model, there were four latent variables: Learner Development Activity Organization (STACT), Assessment of Learner Development Activity (ASSESS), Trisikkha Training (TRISIK) and Model of Learner Development Activity. New pathway (NORMA) by observable variables used in the analysis of all 14 variables. Testing for the consistency of a model of activities for student development according to Buddhist principles for students Under the Office of the Secondary Educational Service Area, the first analysis of the model revealed that the model was inconsistent with the empirical data. Considering that the chi-square value is 204.63 at the degrees of freedom of 71 and the probability (p) is .000 , the square root of the mean square error of the estimate (RMSEA) has the value is equal to .070 .

From the aforementioned analysis results the researcher then adjusted the model by allowing the errors to be correlated. This is a relaxation of the preliminary agreement in the traditional analytical statistics stipulating that the error terms must not be correlated. It is a preliminary agreement in statistics analysis with SEM, which requires that the error term be used in data analysis, and the term of the error is related according to the reality of natural phenomena. Model modification results, the more accurate size, influence and correlation between variables were obtained in the model [4] (Modification indices) and modifications to the model of 16 paths by adjusting 1) Theta-Delta (TD), 2) Theta-Epsilon (TE) and the results of the modifications. This resulted in a model, pattern of student development activities based on Buddhist principles for students consistent with empirical data with detailed analysis results.

When considering the results of the analysis of the model of student development activities based on Buddhist principles for students, it was found that the model was consistent with the empirical data. Consider the statistic used to verify the consistency between the model and the empirical data, the chi-square value is 73.13 , the degree of freedom is 55 , the probability $(p)$ is .052 , that is, the chi-square value that differs significantly from zero, indicating that the main hypothesis that Model, model of activities for learner development according to Buddhist principles for students Developed in harmony with empirical data corresponding to the analysis results, the harmonization index (GFI) is equal to 97 , the modified harmony index (AGFI) is equal to .95, which is closer to 1 and the root index of the mean square. Its residual (RMR) is equal to .01, which approaches zero, and the remainder in the form of the Largest Standardized Residuals score was 2.733, supporting that the research model was consistent with empirical data.

When looking at the precision of the observed variables, it was found that the observed variables had the valuation value between .695 and .873 , with the variable with the highest precision being practicing rational intelligence (STACT3) and following precepts (TRISK1). Equal to equality, 870 followed by training mind to concentrate (TRISK2) training in various services that benefit oneself and the public (NORMA4) cultivate and consciousness to benefit society, (NORMA3) and the needs of learners (NORMA2) have a precision value of .802 and the variable with the lowest precision is the guidance activity (STACT1) had a precision value of .695 overall, the precision of most observable variables was high.

When considering the predictive coefficient (R-SQUARE) of the internal variable structure equation, it was found that the component of the learner development activity (STACT) had a predictive coefficient of .845 , indicating that the variables within the model were learner development activity (STACT), with the Assessment of Learner Development Activities (ASSESS), the variance of the components of the Trisikkha Training was 84.5 percent, show that the variables within the model are learner development activities (STACT), assessment of learner development activities (ASSESS) and self-training according to the principles of TRISIK .96 .5 .

When considering the correlation matrix between the latent variables, it was found that the range, the correlation coefficient between the latent variables, ranged from .868 to .952 , with all the variables having the same direction. (Positive correlation). The variable with the most correlation coefficient was the learner development activity (STACT) and the new model of learner development activity (MORMAL) model with a correlation coefficient equal to 952. A high level of relationship indicates that as learner development activities increase, the model of learner development activities along the new path has increased as well [5].

When considering the direct and indirect influences between the variables in the model, it was found that the relationship between the variables of the learner development activity (STACT) and the new learner development activity model $($ MORMAL) model (correlation size $=.933)$. Separate was direct influence .12 and indirect influence .32 was combined influence .44 indirect influence and total influence on the model of the new learner development activities (MORMAL) were not statistically significant, but the size of the direct influence influenced the prototype of the learner development activities along the new path not statistically significant.

When considering the direct and indirect influences between the variables in the model, it was found that the relationship between the variant of the Learner Development Activity 
Assessment (ASSESS) and the new model of Learner Development Activities (MORMAL) model Indirect influence .43 and indirect influence .12 are combined influences .56 indirect influence and total influence on the model of organizing activities for learner development along the new path (MORMAL) are not statistically significant. But the size of the direct influence influenced the prototype of the learner development activities along the new path All of them have statistical significance [6].

It is noteworthy that the size of the indirect influence between the Learner Development Activity Variable (STACT) and the New Way Learner Development Activity Model (MORMAL) through the Trisikka method was higher than the direct influence. It means that the TRISIK variable is the transmission variable of the causal relationship model, the organization of the student development activities according to Buddhist principles for students under the Secondary Educational Service Area Office and details of the analysis results are shown in the table.

Presenting a model for student development activities according to Buddhist principles under the Office of the Secondary Educational Service Area.

The researcher presented the results of the research in the form of activities for learner development according to Buddhist principles for students under the Office of the Secondary Educational Service Area. There are 4 components of the pattern as follows: 1) the learner development activities, 2) the self-training according to the Trisikkha principle, 3) the prototype of the learner development activities according to the new path, and 4) the assessment of learner development activities. The details are as follows:

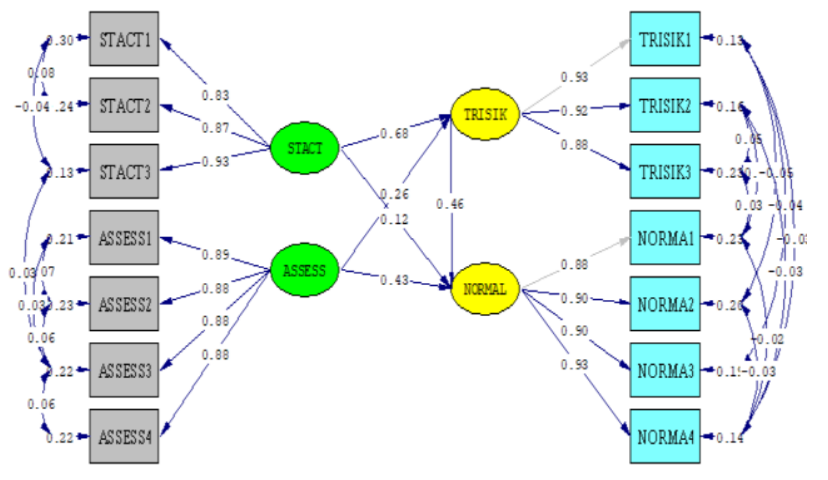

Chi-Square $=73.13, \mathrm{df}=55, \mathrm{p}$-value $=0.05152, \mathrm{RuSEA}=0.029$

Fig.1 A Model of Learner Development Activity Arrangement according to Buddhadhamma for Students

\section{Discussions}

From general information of teachers in educational institutions Under the Office of the Secondary Educational Service Area, the respondents found that it was male, the age between 21-30 years old, Bachelor's degree. There are opinions that are consistent overall that the state of problems in organizing learner development activities for students Under the Office of the Secondary Educational Service Area.
From research Domestic research related to the organization of student development activities for students Under the Office of the Secondary Educational Service Area Found research that can be directly compared, but there is a similar research, namely Krongkaew Chanket (2005) [7] research study on conditions and problems in organizing student development activities in public secondary schools. Pathumthani Province. The results of the research were as follows: 1) The preparation of an educational institution curriculum concerning learner development activities should involve the school committee, parents and community participation and there is a constant supervision, monitoring and evaluation of learner development activities, 2) Establishing clear regulations on learner development activities, set goals for organizing activities for learners to gain a variety of experiences, 3) To implement activities for learner development, teachers should be trained to have knowledge and abilities in organizing learner development activities to allow learners to be independent in decision to create a project, work piece according to potential develop a program of activities for developing learners in various fields in accordance with the needs and interests of the learners, suitable for educational institutions and organize activities that enhance both personality and physical aspects. 4) Providing tools for evaluating the results of learner, development activities. It was also in line with Jatupon Thawahiran[8], studying the condition and problems of the guidance administration using the DEMING circuit (PDCA). The improvement and development audit plan covers all five guidance services, which show that the guidance management work in educational institutions is good and quite complete. This may be due to Basic Education Curriculum, B.E. 2544 (2001) designated line work as a mission that educational institutions must undertake to promote, supervise, and help learners, to be able to learn and develop themselves naturally and to their full potential. School administrators must have attitudes, knowledge and abilities. Have good skills, able to manage advice. As a result, the guidance coordinator teachers perceive their roles and duties and cooperate in fulfilling their roles and responsibilities and cooperate in the effective performance of roles and responsibilities and in accordance with Thanyaniamtang, [9] the study of operating problems, needs of student guidance work and guidelines for the development of the Ban Pong School guidance work under the Office of the Educational Service Area.

1. The operating conditions of the five guidance services still lack clarity in the development and guidance plans. Personnel in charge of the guidance work still lack the development of effective guidance. Data collection classroom teachers prepared in the form of cumulative records. The information is not yet current. Preparation of an information system to disseminate information Made in the form of boards, information signs, brochures, journals, sound lines acquisition of information from magazines, newspapers, radio and television. Counseling services are the duties of the class teacher. There is no specific location and time for consultation. Personal placement services are available to provide assistance in scholarships, lunch, extracurricular activities such as remedial teaching Various assembly activities, performance monitoring, guidance. There is no monitoring and evaluation tool at the end of the 
school year. Summarize and report results according to project plans only. [10]

2. Demand for all five guidance services, it was found that the students wanted the homeroom teacher to collect all aspects of information thoroughly and sort out the need for assistance. Information services Students want the school to distribute the information in a form of voice by line. Organize a video to provide knowledge in various fields such as career, education, knowledge around and take it to the learning resources. Counseling requires that the homeroom teachers have good and friendly relations with the students want to provide assistance in adaptation, poverty, family problems provide a guidance teacher in the guidance room to facilitate counseling. Consultation for a time and after students who have problems come to use the counseling service have the class teacher provide guidance on how far students are receiving academic assistance and personal development.

3. Guidance for the development of guidance work to be effective, found that there are 7 steps, consisting of study of operating conditions, providing five guidance services, determining prospective work conditions in the future establishing guidelines for guidance activities aimed at success guidance analysis for success. The recruitment of responsible persons to prepare the development plan, guidance work, annual action plan monitoring and evaluation of guidance reporting results for further publicity. The research results show that operational conditions, organizing activities for student development basic education level, operations in enhancing student life skills. The school is the main unit of work in life skills. The content of life skills is also included or integrated into the learning materials, eight topics, and in learner development activities, which are guidance activities. Student activities and service activities policy-related departments still focus on academic work stakeholders therefore have to work together in preparing children and youth to have life skills, to be self-reliant and face problems in order to live happily with society [11].

\section{Conclusion}

Presenting a model of learner development activity arrangement according to the Buddhist principles for students, the researcher examined the model by distributing questionnaires, revising and presenting the model from examining the patterns of student development activities according to the Buddhist principles for students under the Office of the Secondary Educational Service Area. It was found that the format of student development activities according to the Buddhist principles for students under the Office of the Secondary Educational Service Area. The overall picture is at a high level. In the activities of developing learners at the highest level showed that the format of student development activities according to Buddhist principles for students under the Office of the Secondary Educational Service Area is consistent with the organization of learner development activities.

\section{References}

[1] Office of the National Primary Education Commission, the learning reform process, Bangkok, 2000.

[2] P. Iamsa-ard, Teaching of Maritime Affairs in Universal Note Reading Skills of Mathayomsuksa 1 Students, Narathiwat, 2007

[3] P. Wilikaew, the development of cooperation between the school and the community In the management of education at Ban Nong Mek School $\mathrm{Na}$ Chueak District Mahasarakham Province, Maha Sarakham, 2007

[4] B. Suthiprapha, Development of English Language Learning Activities to Promote the Independent Study of Mathayomsuksa 5 Students, Mahasarakham, 2008

[5] Bumblebee, an assessment of the organization of guidance activities at the lower secondary school level, expanding educational opportunities. Under the Primary Education Office of Ubon Ratchathani, Ubon Ratchathani, 2012

[6] R. Chartcharoensilkul, Management of Scout-Girl Activities of Outstanding Secondary Schools under the Department of General Education, Roi Et Province, Ubon Ratchathani, 2002

[7] K. Chanket. Conditions and problems in organizing activities for learner development in state secondary schools. Pathum Thani Province. Master of Education Thesis. (Kasetsart University, 2005), pages 123-124.

[8] J. Taohiran. Management of the guidance administration by using the DEMING circuit (PDCA)of educational institutions under the Lopburi Educational Service Area Office, District 1. Master's Thesis. (Thepsatri Rajabhat University. 2005.

[9] Thanyaniamtang, Development of the Bangpong School's guidance work Under the Office of Chiang Rai Educational Service Area, Region 3, Chiang Rai Province. Master of Education Thesis. 
Chiang Rai: Chiang Rai Rajabhat

University, 2004.

[10] A. Intarapanya, Problems in organizing learner development activities in public secondary schoolsNonthaburi Province, Bangkok, 2005.

[11] Jiang, Guang-Rong, Class Environment and its Relations to Teacher Style and Student Development,Dissertation Abstracts International, 62 (9): 2970-A; March, 2002. 